\title{
R\&D and application of voltage sourced converter based high voltage direct current engineering technology in China
}

\author{
Guangfu TANG ( $ه$ ), Zhiyuan HE, Hui PANG
}

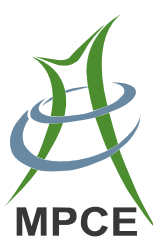

\begin{abstract}
As a new generation of direct current (DC) transmission technology, voltage sourced converter (VSC) based high voltage direct current (HVDC) has been widely developed and applied all over the world. China has also carried out a deep technical research and engineering application in this area, and at present, it has been stepped into a fast growing period. This paper gives a general review over China's VSC based HVDC in terms of engineering technology, application and future development. It comprehensively analyzes the technical difficulties and future development orientation on the aspects of the main configurations of VSC based HVDC system, topological structures of converters, control and protection technologies, flexible DC cables, converter valve tests, etc. It introduces the applicable fields and current status of China's VSC based HVDC projects, and analyzes the application trends of VSC based HVDC projects both in China and all over the world according to the development characteristics and demands of future power grids.
\end{abstract}

Keywords Voltage sourced converter based high voltage direct current (VSC based HVDC), Two-level converter, Modular multi-level converter (MMC), Direct current grid (DC grid)

\section{Introduction}

The transmission technology has gone from DC to AC, $\mathrm{AC}$ to $\mathrm{DC}$ and then to coexist technological evolution. With the electrical and electronic technological

Received: 30 October 2013/Accepted: 7 January 2014/Published online: 22 February 2014

(C) The Author(s) 2014. This article is published with open access at Springerlink.com

G. TANG, Z. HE, H. PANG, State Grid Smart Grid Research Institute, Beijing 102200, China

$(\bowtie)$ e-mail: gftang@sgri.sgcc.com.cn improvement, as a new generation of DC transmission technology, flexible DC may help to solve many difficulties that the current AC/DC transmission technologies face, and provide a new solution $[1,2]$ for innovation of transmission methods and establishment of future grid.

The earliest concept of voltage sourced converter (VSC) based high voltage direct current (HVDC) transmission was proposed by Boon-Teck et al. from Canada McGill University $[3,4]$ in 1990. The operating principle of this concept is that the $\mathrm{AC}$ active power and reactive power may be controlled by switching on and off the VSC or changing the voltage phase angle and amplitude so as to effectively overcome some existing defects. This concept was formally named as "VSCHVDC" in the International Conference on Large HV Electric Systems (CIGRE) and America Electrical and Electronic Project in 2004, also as HVDC Light [5], HVDC Plus and HVDC MaxSine by the international companies of ABB, Siemens and Alstom respectively. It has also been named as high voltage direct current flexible (HVDC Flexible) in China.

Early VSC based HVDC (referred to as HVDC Flexible in this paper) adopts two-level or three-level converter technology, but it always has several defects, such as high harmonic contents and high switching losses, etc. With the continuous growing demand for high voltage level and power transmission capacity, these defects are represented more and more obviously, which become a bottleneck for application of the twolevel or three-level technology. Therefore, the future of the twolevel or three-level technology may be only used for low power transmission or on some special occasions such as offshore platform power supply or variable speed drives, etc. In 2001, R. Marquart and A. Lesnicar from Bundeswehr Munich University of Germany jointly proposed a modular multi-level converter (MMC) topology [6, 7]. The proposal and application of the MMC technology is an important milestone in the history of technical development for HVDC Flexible engineering. The occurrence of such technology improves the operational 


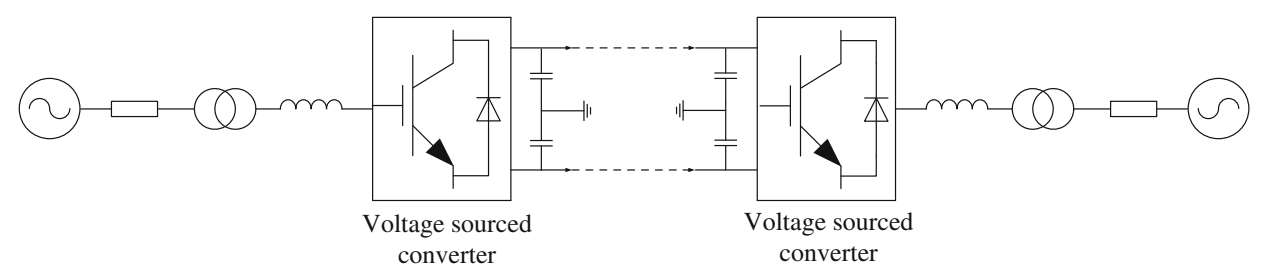

(a) Symmetric monopole system

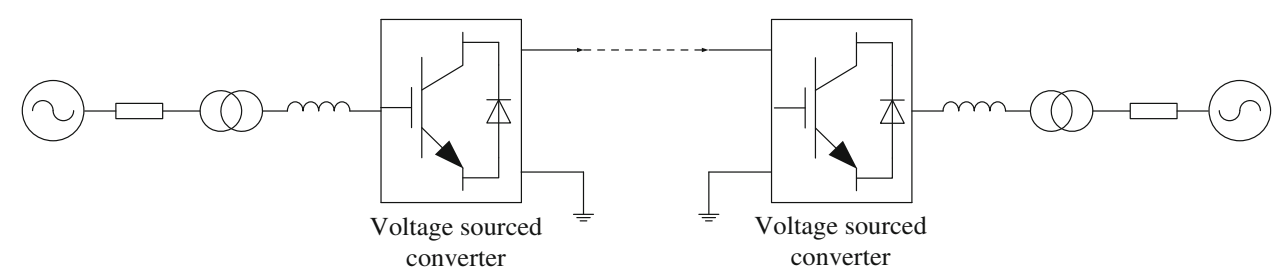

(b) Asymmetric monopole system

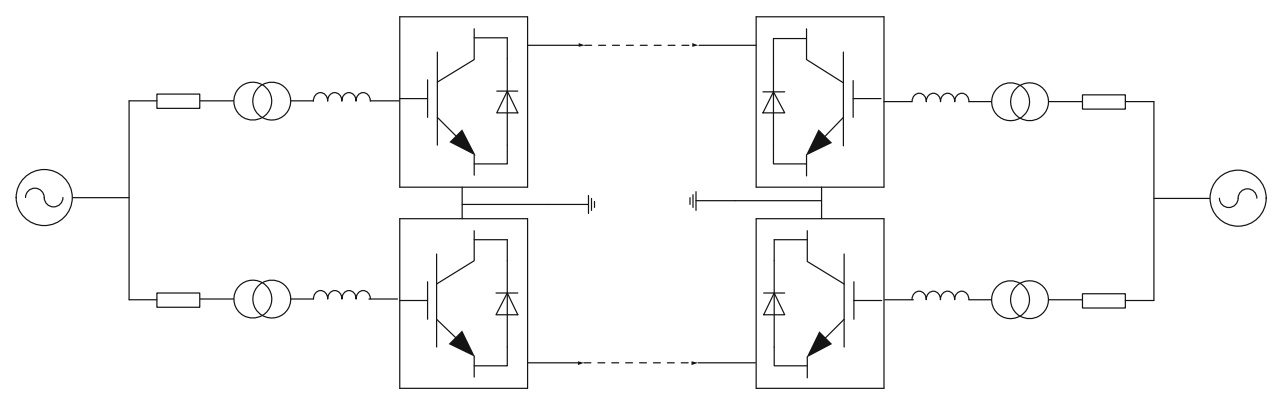

(c) Symmetric bipole system

Fig. 1 Typical two-terminal HVDC Flexible system

benefits of HVDC Flexible projects, greatly promotes the development and application of the technology.

Based on three aspects, i.e. engineering technology, application and future development, this paper firstly analyzes the challenges that the technical development of HVDC Flexible projects currently faces, future development orientation of relevant technology and expected targets. Secondly, it briefs China's HVDC Flexible projects and points out the technology and application characteristics. Finally, it analyzes the potential development of the HVDC Flexible projects and the project application prospect both in China and all over the world.

\section{HVDC flexible technology}

\subsection{HVDC flexible system}

The HVDC Flexible system with two-level or threelevel converter configurations usually adopts the grounding point on the DC side, but on the AC side while the system with MMC configuration. Regardless the grounding location a monopole- symmetric system is always used for the HVDC Flexible system. During normal operating conditions, no current passes through grounding path thus it is no need to set special grounding pole, but when the DC line or converter fails, the whole system will stop running. Furthermore, it may forms a monopole asymmetric structure via grounding path or metallic return, which is similar to a pole of a traditional HVDC transmission system.

In order to increase the power capacity and voltage level of the HVDC Flexible system, and to meet the requirements of super-high voltage and remote large power transmission, the converter of the monopole convertor station may also consist of several small converter units in series or/and parallel connections. As shown in Fig. 1, two asymmetric monopole systems may form a bipole symmetric system via series connections, which is similar to a traditional HVDC transmission system.

Transformers used for a bipole system are required to withstand the transformer DC bias voltage caused by the asymmetry of DC voltage. Unlike conventional DC transformers, the transformers are not required to withstand the 


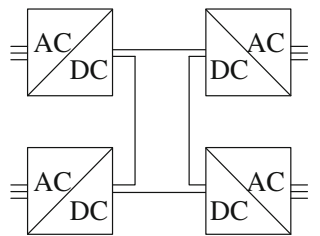

(a) Series connection

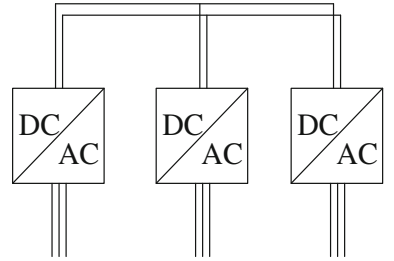

(b) Radioactive parallel connection

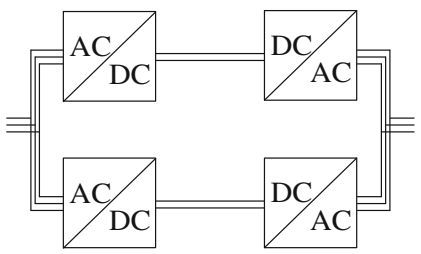

(c) Looped parallel connection

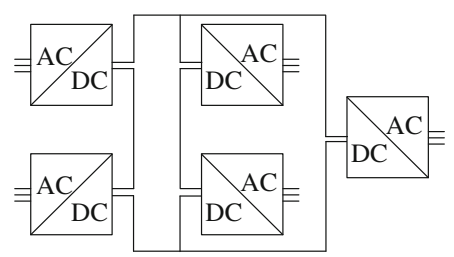

(d) Parallel and series connection type

Fig. 2 Typical connection diagrams of multi-terminal HVDC

harmonic components generated by the convertor stations. At present, in order to reduce the fault incidence on the DC side, the HVDC Flexible transmission projects usually use cables as the transmission lines, which is the main reason that the monopole structure is used in the HVDC Flexible transmission system. In this way, it is more reliable to use single converter and can also reduce the project costs.

The multi-terminal flexible DC transmission system is generally connected in parallel so as to ensure the converters are operated in the same DC voltage level. The parallel connected multi-terminal flexible DC networks can also be divided into two basic structures, i.e. star and ring types. Other complicated structures can be regarded as the extension and combination of these two structures. There are four kinds of topological structures as showed in Fig. 2.

Compared with the series connection type, the parallel connection type has less line losses, larger adjusting range, more accessible insulation coordination, more flexible extension mode and significant economic efficiency. Therefore, all existing operational multi-terminal DC transmission projects use the parallel connection mode.

\subsection{HVDC flexible converter technology}

Based on the equivalent characteristic of bridge arms, the HVDC Flexible converter techniques can be divided into controllable switch type and controllable power supply type. The converting bridge arm of the controllable switch type converter is equivalent to the controllable switch, controlling the turn-on and turn-off of the bridge arms by appropriate pulse width modulation techniques and transmitting the voltage from the DC side to the AC side. The energy storage capacitors of the controllable power supply type converter are-distributed in different bridge arms. Their converting bridge arms are equivalent to the controllable voltage sources which can indirectly change the output voltage on the $\mathrm{AC}$ side by changing the equivalent voltage of the bridge arms. Both equivalent circuits shown in Fig. 3 and Fig. 4 show the output waveforms at the AC outlets of the two topological converter valves [8-10].

The controllable switch type converter is represented typically by a two-level converter and its topological structure and operating control are relatively simple. But the switching frequency and losses of the converter are higher, and the harmonic contents on the AC and DC sides are larger resulting in multiple filter units required. Although a 3-level converter has relatively lower harmonic contents in the output voltage waveform, and its switching frequency, total harmonic level and losses have also been reduced, the converter has complicate topological structure, higher costs and lower reliable system. In addition, as each bridge arm of switch type voltage sourced converter is directly connected by a large number of switching devices in series, it needs to solve the static and dynamic voltage sharing and other problems caused by the turn-on and turnoff of the switching devices.

Modular multi-level (MMC) converters are the typical representative of controllable power supply type converters [11-13]. The equivalent output voltage is achieved by changing the number of the series connected sub-modules into the bridge arms. As shown in Fig. 5, this type of converters can also be divided into semi-bridge mode, full bridge mode, clamping twin module mode and other diversified forms according to the types adopted in submodules. In addition, the cascaded two-level converters (CTL) are cascaded by semi-bridge circuits, so they also belong to the controllable power supply type converters in nature [14].

When the sub-modules in the bridge arms exceed a certain number and the output voltage waveform of the converter is approximated to a sinusoidal step waveform, filtering devices are not required. Compared with the twolevel converters, the MMC converters have the following outstanding advantages: (1) modularization design which can make the upgrade of voltage levels and capacities easier; (2) the switching frequency and stress of devices are reduced significantly; (3) the harmonics and total harmonic distortion in the output voltage are greatly reduced and filtering devices are not required on the AC side. 


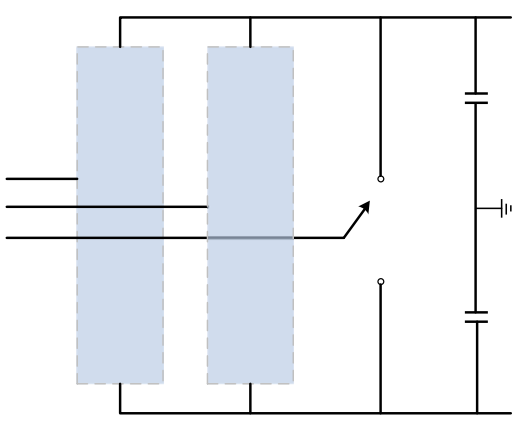

(a) Controllable switch type

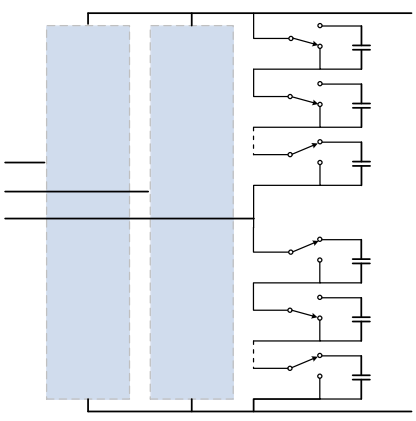

(b) Controllable power supply type

Fig. 3 Equivalent circuits of switch-controllable converter and voltage-controllable converter

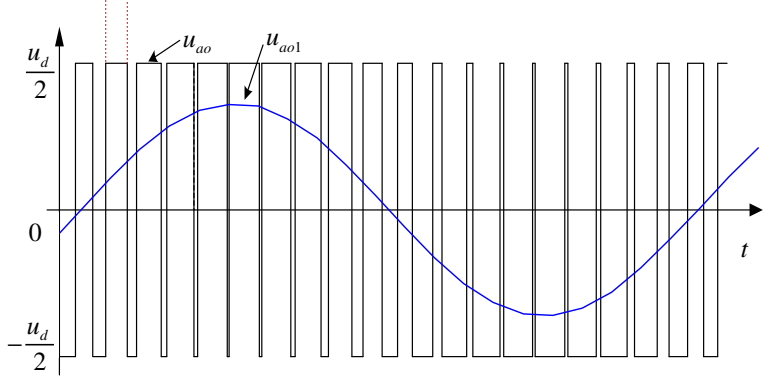

(a) Controllable switch type

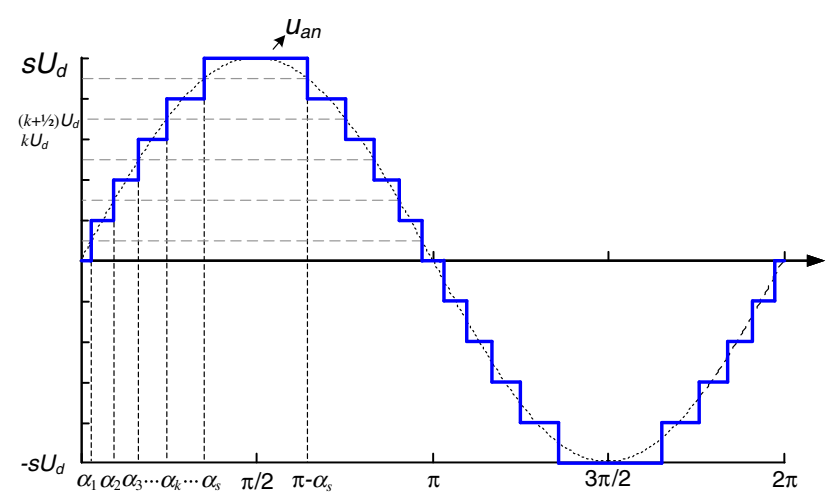

(b) Controllable power supply type

Fig. 4 Output waveform in converter AC side

Comparing with the two-level converters, the disadvantages of the MMCs are: (1) as there are a large number of submodules in series connection in each bridge arm, the valve control system needs to process a large amount of data in each period, therefore high requirements are needed for the control system; (2) distributed energy storage capacitor increases the balance control for the sub-module capacitor voltages [15]; (3) the energy is not evenly distributed in each bridge arm, which destroys the internal stability within the sub-modules and causes the distortion of the current waveform.

At present, the converter techniques in engineering application, no matter the two-level type or the semi-bridge
MMC, all have a prominent problem, i.e. it is unable to achieve the isolation of $\mathrm{AC}$ and DC systems under DC fault conditions. However the full bridge and clamping twin submodule MMCs can still support the AC voltage to achieve the inhibiting effect on the short-circuit current on the AC side when the DC voltage is rapidly reduced, because they can make the equivalent output voltage of the bridge arms become negative [16].

\subsection{Control and protection of HVDC flexible}

The flexible DC control and protection system, as the core to ensure normal operation of the system, is used to realize the control function of normal operation of the system and the protection function under faults. The control and protection system includes the convertor station level control and protection system and the converter valve level control and protection system.

Unlike the conventional DC transmission, the converter valve level control and protection system in HVDC Flexible is far more complicated. Especially, in the MMC HVDC Flexible system, the convertor station level controller (called pole controller or station controller for short) just undertakes a part of control and protection function. The control and protection for the valves relies more on the converter valve level controller. The functions include producing the control signals of converter valve submodules, handling and summarizing the data, achieving the protection of converter valves and so on, according to the signal requirements of convertor station level control (as shown in Fig. 6). Therefore, the HVDC Flexible control and protection system is usually required to achieve the high speed sync control in nanosecond level to meet the high real-time requirements of HVDC Flexible control system.

In addition to realizing the normal start and shut down of the system, the flexible HVDC convertor station level control system also includes the steady power control and 


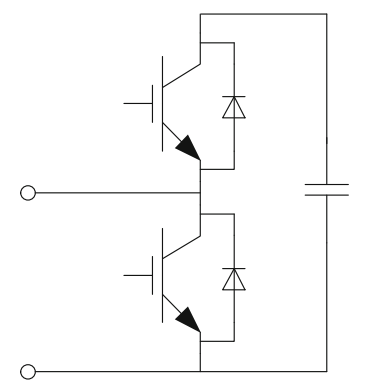

(a) Semi-bridge type

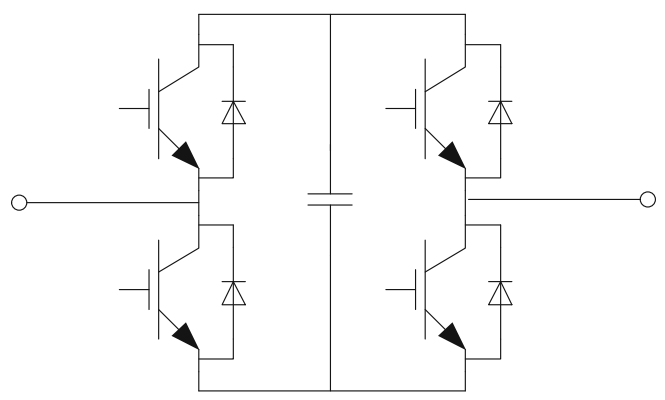

(b) Full bridge type

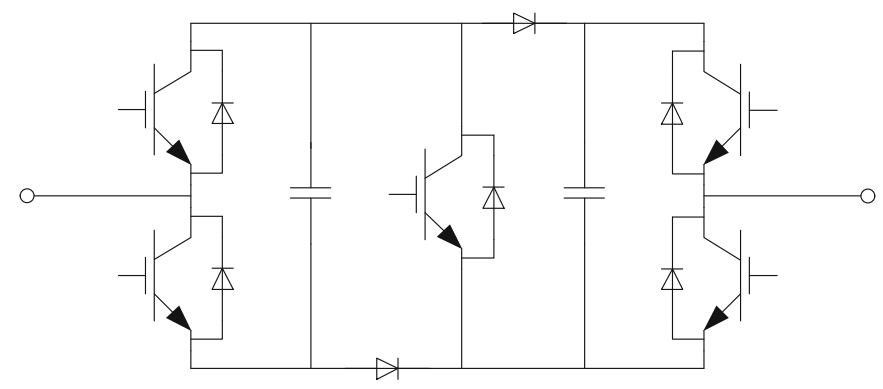

(c) Clamping twin module type

Fig. 5 Sub-module topologies of modular multi-level converter

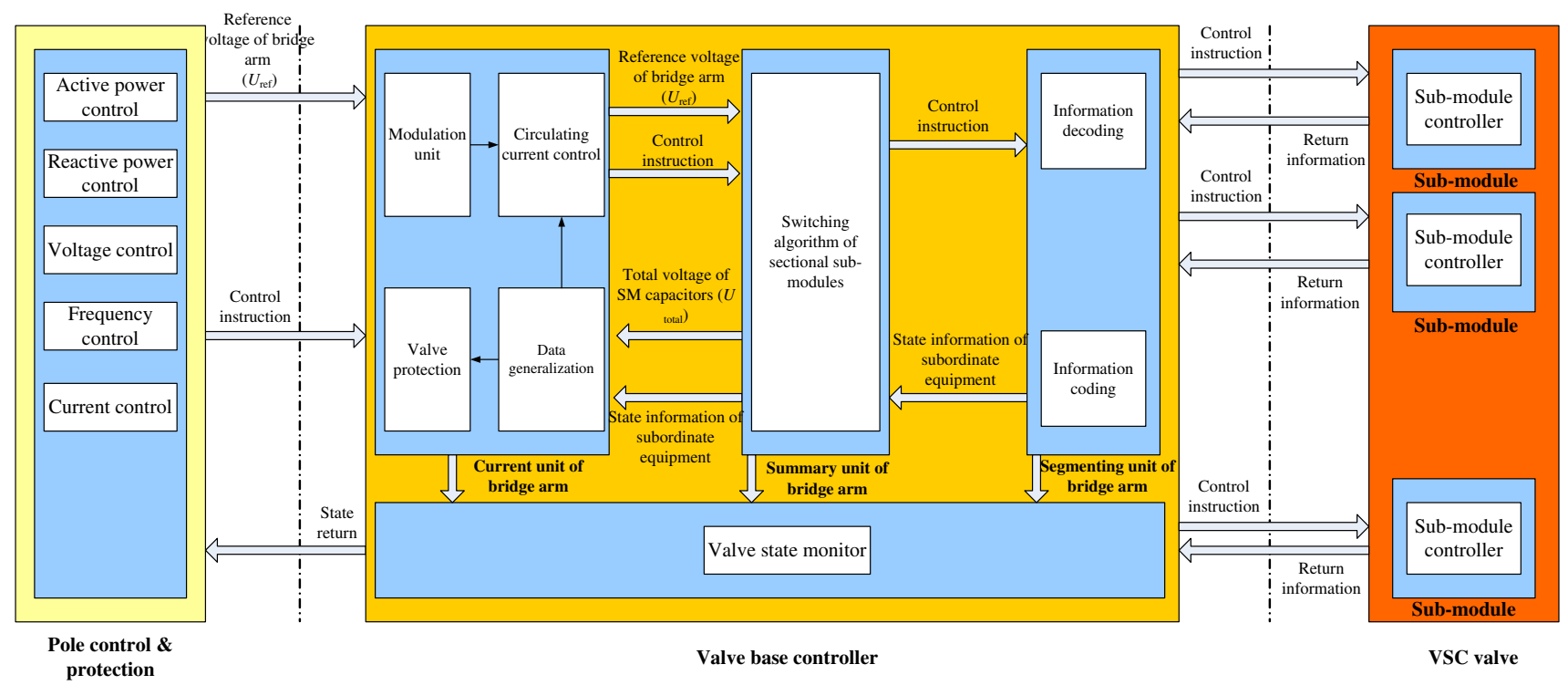

Fig. 6 Station \& converter control system

adjustment. Its power controller includes an active power controller and a reactive power controller. The active power controller includes active power control and DC voltage control and the reactive power controller includes reactive power control and AC voltage control. Generally speaking, the normal operation of two-terminal HVDC Flexible system needs one station to control the DC voltage and the other terminal to control the active power, while the two-station reactive adjustments are mutually independent and can freely choose to control the reactive power or the AC voltage. On the control strategy, no matter the two-level or MMC technique is used, the equivalent mathematical model on the AC side is similar. Therefore, the same station level control strategy can be used. In numerous station level control strategies, the DC vector control strategy has become the mainstream control technique of the VSC for its high current responding speed and accurate current control effect [17-19]. 
The valve level control is the main difference of control system between MMC, HVDC Flexible, conventional HVDC and two-level HVDC Flexible. The valve base controller (VBC) in the HVDC Flexible is the middle connector to realize the station level control system and low-level sub-module control. It is used to realize the control, protection and monitoring of the valve arms and the communication between the station control system and converter valve. Meanwhile it is also used to realize the balance function of the sub-module capacitor voltage and circulation control function, which is the key to ensure the normal operation of the MMC HVDC Flexible system. Because the valve arm in the system with high voltage and large capacity is generally made up of hundreds of submodules, in order to ensure the voltage balance between each sub-module, VBC has a high requirement on the data disposal speed of the sub-modules, usually less than $100 \mu \mathrm{s}$. It is a huge challenge for the valve control design to achieve this high speed control balance technique of large-scale sub-modules. The unique circulation phenomenon of modular multi-level technique will cause the increase of the converter valve current stress and the loss level. If serious enough, it may make the system lose the balance and be unable to operate normally. For this reason, the design of circulating current control strategy is also a key factor in valve control.

The main function of HVDC Flexible protection system is to rapidly trip a fault or abnormally operating equipment in the system under the fault operating conditions, so as to ensure the safe operation of the remaining health system.
As shown in Fig. 7, the protection system can be roughly divided into AC-side protection, converter protection and DC-side protection.

\subsection{Cable technology of HVDC flexible}

It is difficult for the HVDC Flexible system to trip faults occurred on the DC side, so DC cables are usually used in the established HVDC Flexible projects to reduce the fault occurring rate.

Compared with AC cables, the conductors of the DC cables do not have skin effect and proximity effect, so even though they transmit large current, the complex segmentation conductor structure is not required for them. The electric field intensity of DC cables is distributed in direct proportion to the resistance coefficients of insulation which will change along with the temperature. If the load increases, the electric field intensity on the insulation surface will gradually increase. Therefore, the maximum load allowed by the DC cables should not make the electric field intensity on the insulation surface exceed its permissible value, i.e. not only the maximum working temperature of the cables shall be considered but also the temperature distribution of the insulating layer.

Compared with traditional DC cables, the DC cables used for the HVDC Flexible are not required to withstand the reversal of polarity of the voltage. Therefore, in some sense, the technical requirement to the cables for HVDC Flexible is lower than that of the traditional DC cables.

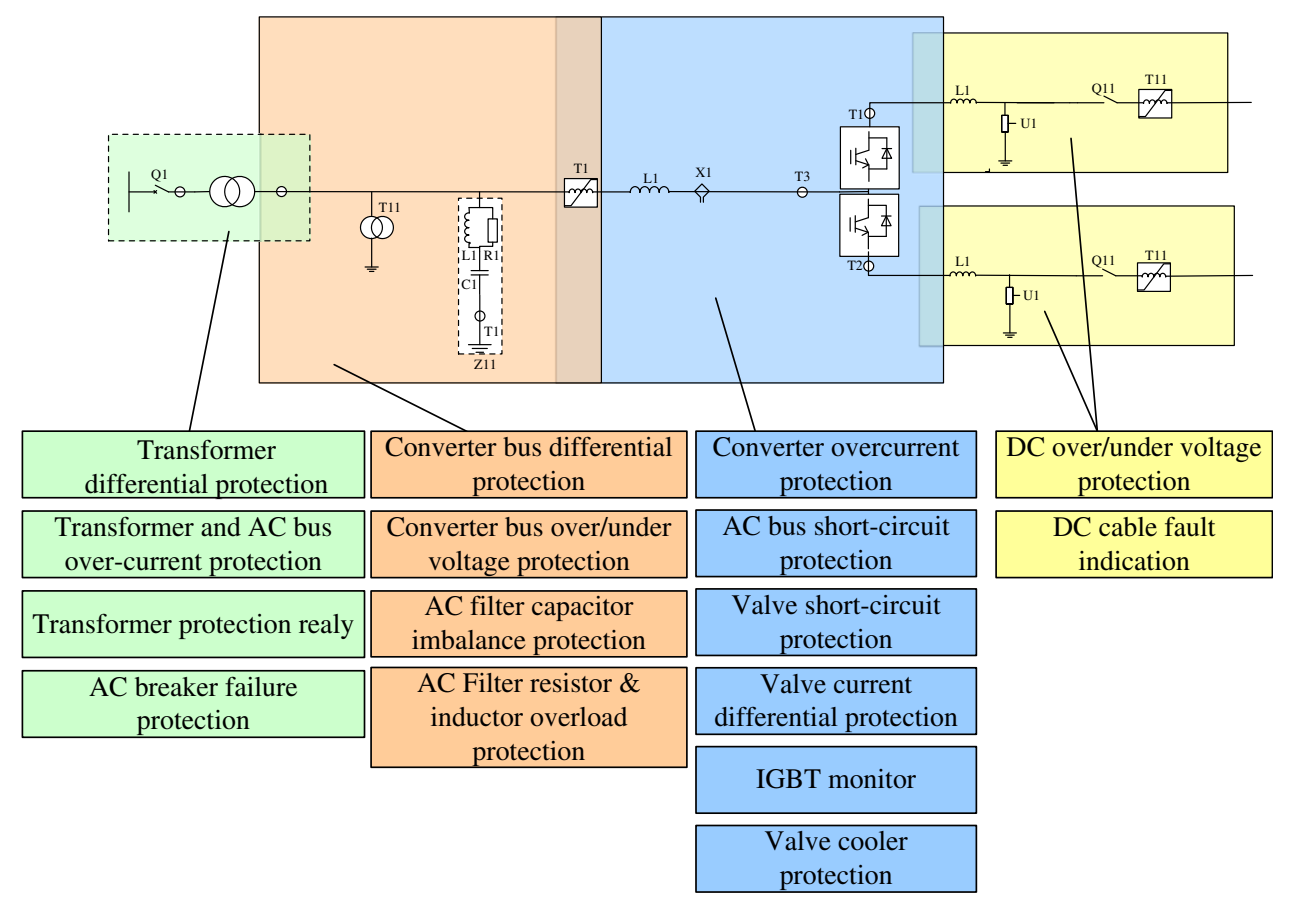

Fig. 7 Typical protection zoning of flexible HVDC system 


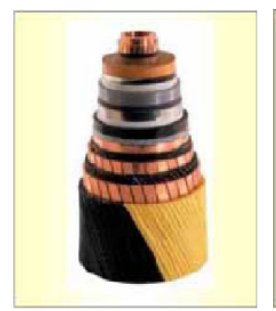

(a) Oil filling cable

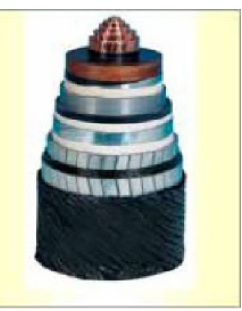

(b) MI insulation cable

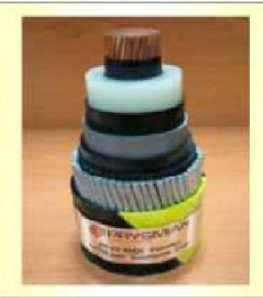

(c) XLPE cable
Fig. 8 Three types of DC cable technology

At present, based on the different insulation forms the cables used for HVDC Flexible are mainly divided into three different types, i.e. self-contained oil filling (SCOF) cable, mass-impregnated (MI) cable and cross-linked polyethylene (XLPE) cable, as shown in Fig. 8.

The self-contained oil filling cable uses a very mature technique and its rated voltage level can reach $800 \mathrm{kV}$. The cable is filled with low viscosity cable oil and tits insulating paper is made from brown paper of coniferous wood pulp. When the cable is damaged due to the external force resulting in oil leakage, it is unnecessary to stop the operation to deal with the leakage immediately. The cables can keep normal operation by adding oil form the oil compensating equipment. But form the environment point of view, the cable oil leakage will cause environmental pollution, especially the pollution caused by the seabed cables to the marine environment. The oil filling cable needs fuel tanks and other accessory equipment, so the workload of its operation and maintenance is large and the cost is also high.

The mass-impregnated (MI) cable is also using a very mature technique, which has been used in the DC transmission system for more than 100 years. The MI cable is suitable for up to $500 \mathrm{kV} \mathrm{DC}$. At present, even though the longest MI cable route is $580 \mathrm{~km}$ for NorNed project built in 2008, its length for use is almost unlimited. Its operating maximum temperature is $55^{\circ} \mathrm{C}$ and it is not suitable to operate in high temperature different conditions.

The XLPE insulated cable for HVDC Flexible is made of cross-linked polyethylene insulated material. Through ultra-clean and high purity technology or adding nanometer materials into the cross-linked AC cable insulation, the space charge problem of cross-linked DC cable has been solved. Due to the high softening point, the cable has small thermal deformation, high mechanical strength in high temperature and good thermal aging resistance of crosslinked polyethylene, thus its highest operating temperature can reach up to $90{ }^{\circ} \mathrm{C}$, and its short-time allowable temperature can reach up to $250^{\circ} \mathrm{C}$. The XLPE insulated HVDC Flexible cable is extruded into new-style monopole cable by three lays of polymeric materials. The insulating layer is extruded simultaneously by the conductor shielding layer, the insulating layer and the insulation shielding layer. The middle conductor is generally the single-core conductor made of aluminum or copper [20]. The highest parameters of current HVDC Flexible XLPE cable which can meet the project application requirements are $320 \mathrm{kV}$ and 1,560 A. The flexible DC cables with a voltage level of above $500 \mathrm{kV}$ are in developing now. China has currently completed the development of $160 \mathrm{kV}$ flexible DC cables and already apply them into the practical engineering application; the $200 \mathrm{kV}$ flexible DC cables have already passed the type tests and are in production and the $320 \mathrm{kV}$ flexible DC cables have been started to be developed, but it still needs certain time to put them into practical application.

\subsection{HVDC flexible test technology}

The testing technology of HVDC Flexible mainly includes the testing technology of the converter valves and valve control equipment. Specifically to the converter valve testing technology, the CIGRE B4.48 working group in-charged by a Chinese expert explained and analyzed the stresses suffered by the converter valves in different working conditions in detail and made relevant testing suggestions in their report (447-Components Testing of VSC System for HVDC Applications). IEC 62501 has currently formulated relevant testing standards for converter valves. China has already had relevant capacities to carry out the HVDC Flexible converter valve type tests and completed the type tests for the $1,000 \mathrm{MW} / \pm 320 \mathrm{kV}$ converter valves.

The HVDC Flexible converter valves are divided into switch type and controllable voltage source type and converters are voltage source type. Their basic operating principles are different from those for the conventional HVDC. Therefore, the transient state and steady state working conditions of HVDC Flexible converter valves are quite different from those of conventional HVDC converter valves. Due to the different stresses suffered by the flexible converter valves, the test items, methods and equipment for the originally conventional DC converter valves are almost not applicable. Therefore, it is necessary to undertake further researches on the operating principles of valves and the voltages, currents, heat, forces, other stresses and waveforms on the power electronic devices and components, so as to recommend relevant test items and equivalent testing methods.

In the steady state operation, the voltage and current stresses suffered by the HVDC Flexible converter valves are the super-impose of continuous DC and AC components. During transient, under the clamping action of submodule capacitor voltage, there will be short-term 
capacitor discharge current in the converter valves and the discharge current is gradually reduced due to the protection actions.

The type test items of HVDC Flexible converter valves mainly include insulating type tests and operation type tests. The insulating type tests can also be divided into valve ground insulation tests and valve body insulation tests. The details are given in Table 1.

The valve control test technology is the important link to test the function and reliability of the valve control system. From the perspective of the HVDC Flexible valve base controller test system, as the trigger signals for all devices in a bridge arm in the conventional DC are identical, so the test can be carried out with a single equivalent scheme of thyristor devices. But as the trigger signals for each submodules in a bridge arm in the HVDC Flexible are different, the valve control system of HVDC Flexible needs to

Table 1 Main test items for HVDC Flexible converter

\begin{tabular}{|c|c|}
\hline Test items & Contents \\
\hline \multirow[t]{4}{*}{$\begin{array}{l}\text { Type tests of insulation to ground for } \\
\text { HVDC Flexible converter valves }\end{array}$} & $\begin{array}{l}\text { AC voltage withstand test } \\
\text { of valve support }\end{array}$ \\
\hline & $\begin{array}{l}\text { DC voltage withstand test } \\
\text { of valve support }\end{array}$ \\
\hline & $\begin{array}{l}\text { Operation impulse test of } \\
\text { valve support }\end{array}$ \\
\hline & $\begin{array}{l}\text { Lightning impulse test of } \\
\text { valve support }\end{array}$ \\
\hline \multirow{2}{*}{$\begin{array}{l}\text { Insulation type tests of HVDC Flexible } \\
\text { converter valves }\end{array}$} & DC voltage withstand test \\
\hline & $\begin{array}{l}\text { AC \& DC voltage } \\
\text { withstand test }\end{array}$ \\
\hline \multirow[t]{6}{*}{$\begin{array}{l}\text { Operation tests of HVDC Flexible } \\
\text { converter valves }\end{array}$} & $\begin{array}{l}\text { Maximum operating load } \\
\text { test }\end{array}$ \\
\hline & $\begin{array}{l}\text { Maximum transient } \\
\text { overload operation test }\end{array}$ \\
\hline & Minimum DC voltage test \\
\hline & $\begin{array}{l}\text { Valve short circuit current } \\
\text { test }\end{array}$ \\
\hline & $\begin{array}{l}\text { Valve over-current turn- } \\
\text { off test }\end{array}$ \\
\hline & $\begin{array}{l}\text { Valve electromagnetic } \\
\text { interference test }\end{array}$ \\
\hline
\end{tabular}

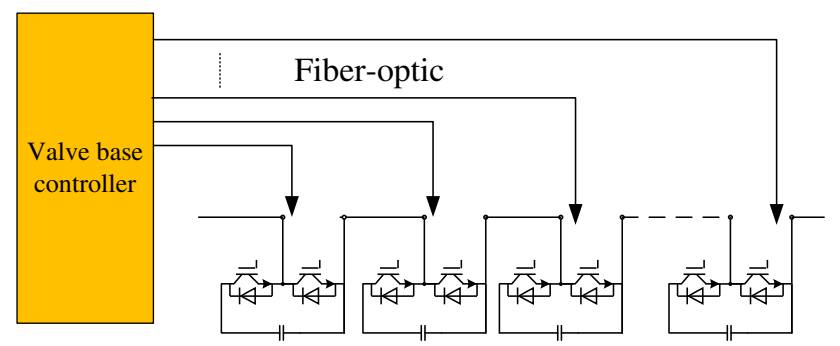

Fig. 9 Diagram of test system for valve base controller provide different control command for each convertor submodule. The original equivalent test methods for the valve system are not suitable to the HVDC Flexible converter valve control system (see Fig. 9).

The HVDC Flexible digital-analog hybrid simulation system constructed by dynamic simulation technique is currently the important technology means to study the MMC HVDC Flexible system. Dynamic modelling system can accurately simulate the dynamic behaviors of the HVDC Flexible converter valves, and provide real-time test function for the valve control system and pole control and protection system, as shown in Fig. 10.

At present, China has built a MMC HVDC Flexible realtime simulation system with up to 3,000 nodes. It can be used to undertake online tests and system simulation of the valve base control equipment of $\pm 320 \mathrm{kV}$ voltage level and within $100 \mu \mathrm{s}$. The simulation systems for the projects of $\pm 500 \mathrm{kV}$ and high, the multi-terminal HVDC Flexible and DC grid have been basically constructed and accomplished.

The digital real-time simulation system can finish the power grid modeling and realize the simulation of electromagnetic transients of the HVDC Flexible, such as startup, shutdown, operation mode switching process, low frequency oscillation phenomena and faults. It can also be used to simulate the unlock and lock tests of the valve control system, the communication tests between the valve control and pole control equipment, the start-up/shutdown control tests of the converter valves, the valve fault simulation tests and so on. The digital real-time simulation is the necessary means to research and test the HVDC Flexible system. It can also be combined with the dynamic simulation tests to constitute the simulation test platform with more thorough functions and reduce the development cost and time of dynamic test system [21, 22].

\section{Application status of HVDC Flexible projects in China}

\subsection{Application fields of HVDC Flexible projects}

Based on HVDC Flexible technology characteristics, the constituted system is widely used in the fields of renewable energy source (RES) integration, island power supply, urban power supply, grid interconnection, etc.

The use of HVDC Flexible technology for the integration of wind power, solar energy and other RES with high power fluctuation can reduce the voltage fluctuation caused by the power fluctuation of RES and improve power quality. When a short circuit fault occurs in the AC system, the HVDC Flexible system can efficiently isolate the fault to ensure the stable operation of the RES. According to the 
calculation of CIGRE, the HVDC Flexible system is the best solution for an off-shore wind farm if the off-shore distance is over $60 \mathrm{~km}$.

The use of HVDC Flexible technology in power supply to islands and offshore drilling platforms can give full play to its self-commutated technical advantages. Meanwhile, with respect to the AC circuits, DC circuits have advantages of lower investment and operating costs, no additional compensation equipment required for long distance power transmission and so on.

The use of HVDC Flexible technology in power supply to the urban center can not only quickly control the active power and reactive power to solve the voltage flicker and other power quality issues; but also provide system damping to improve the stability of the system and "black start function" when a serious fault occurs. In addition, the use of buried DC cables in HVDC Flexible will not cause alternation electromagnetic field and oil pollution, can achieve the capacity expansion and reformation of the urban power grid and can meet the urban central demand requirements and

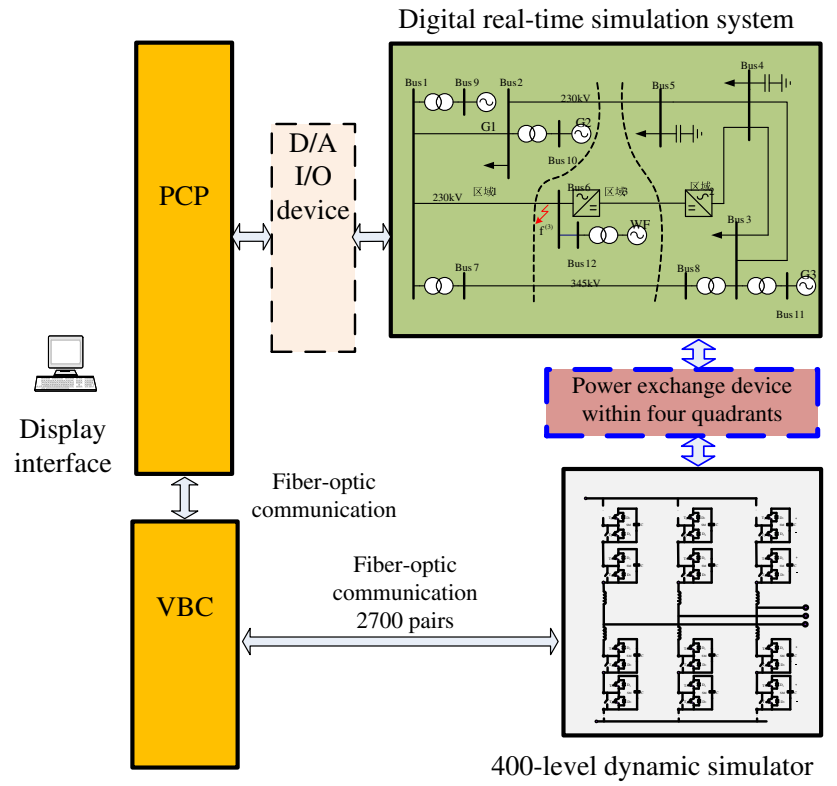

Fig. 10 Diagram of real-time hybrid simulation system environmental protection and energy saving requirements under the circumstances of no electromagnetic interference and no influence to the city appearance.

The use of HVDC Flexible technology to realize the power grid interconnection can not only complete the power exchange function between power grids, but also solve dynamic stability, black start of power grids and excessive short-circuit current and other issues in a largescale power grid. All of these advantages of the HVDC Flexible rely on its quick and independent reactive power adjustment, "black start" capability, no short-circuit current indeed and other technical characteristics. Furthermore, the dimension of a HVDC Flexible convertor station is smaller than that of a conventional DC convertor station with the same capacity, thus the HVDC Flexible convertor station can be built close to the load center.

\subsection{Application status of HVDC Flexible project in China}

At the beginning of 2006, several Chinese institutes started to research the HVDC Flexible technology. They have obtained a series of achievements in basic theoretical research, key technologies, core equipment development, test capability building, engineering, system integration etc. The China's first HVDC Flexible demonstration project was commissioned into operation in Nanhui of Shanghai in July, 2011 [18, 23].

The modular multilevel converter (MMC) structure is used in Shanghai Nanhui HVDC Flexible demonstration project. It has a capacity of $20 \mathrm{MW}, \pm 30 \mathrm{kV}$ DC with a transmission length of approximately $8 \mathrm{~km}$ [23]. Nanhui wind power plant has been integrated in Shanghai Power Grid through this project (see Fig. 11). To verify the effect of the HVDC Flexible system in wind power integration, the manual shot-circuit tests were carried out, and the results indicated that this project can substantially improve the low voltage ride through capacity of wind power plants.

In order to meet the increased power demands of the economy development in the south of Dalian downtown,

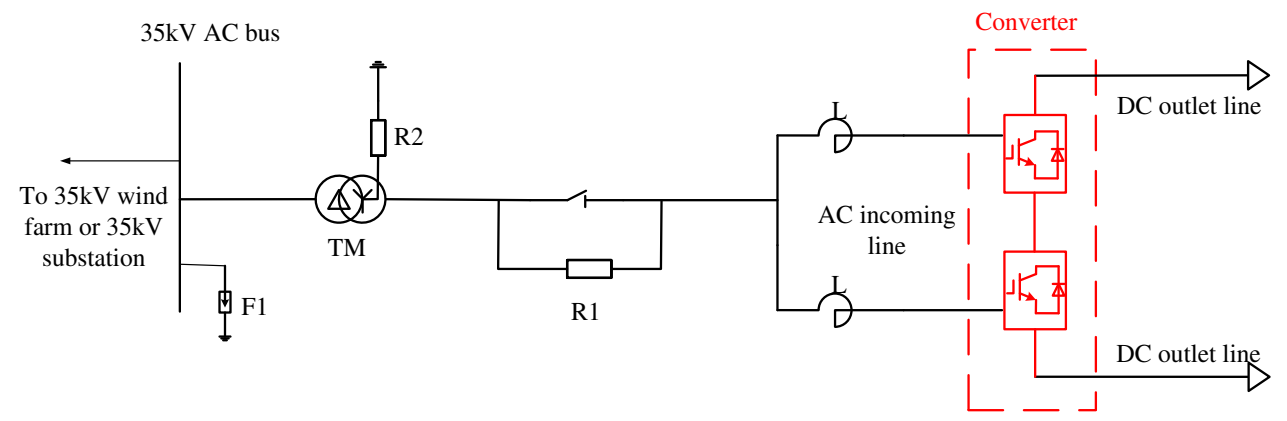

Fig. 11 Circuit diagram of Nanfeng station in Shanghai Nanhui project 
avoiding the serious influence of natural disasters on the urban power supply and eliminating the potential safety hazards of power grids, the Station Grid Corporation of China (SGCC) started to construct a HVDC Flexible project which will to connect the north major network and the harbor east areas of the southern part downtown of Dalian city in 2012. This project has a rated capacity of 1,000 MW, a direct current (DC) voltage of $\pm 320 \mathrm{kV}$ [24], and a delivery transmission distance of about approximately $60 \mathrm{~km}$. By end of December 2012, the world's first set of $1,000 \mathrm{MW} / \pm 320 \mathrm{kV}$ converter valves and valve base controllers were developed relying on this project, and went through the witness tests of DNV KEMA (see Fig. 12). Meanwhile, relying on this project, China has built the world's largest dynamic model platform with 400 levels which effectively verified the validity of Dalian valve control system design and all kinds of functions. On the basis of engineering design, China has grasped a whole set of packaged design techniques on high-capacity HVDC Flexible system, convertor station construction techniques and system operation and maintenance techniques.

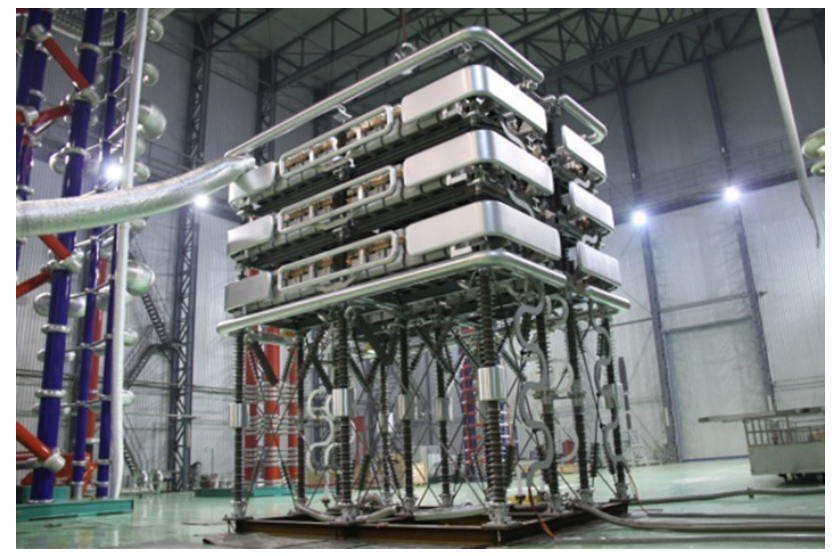

Fig. $121,000 \mathrm{MW} / \pm 320 \mathrm{kV}$ HVDC Flexible converter valve
In order to improve the power distribution reliability and operation flexibility of Zhoushan Power Grid and consider the digestion integration and save of the rich wind power resources in Zhoushan islands, the Station Grid Corporation of China SGCC has planned to construct a 5-terminal HVDC Flexible project which is scheduled to be completed in 2014. This project contains 5 convertor stations with a total system capacity of 1,000 MW, and the largest convertor station will have a capacity of $400 \mathrm{MW}$ and a direct current (DC) voltage class of $\pm 200 \mathrm{kV}$ (see Fig. 13). This project is the HVDC Flexible project [25] with the largest terminal number in the current world currently. It can meet the increasing load demands in Zhoushan region, becomes the second power source in the power supply of the northern islands and improves the power distribution reliability after being completed. It has the advantages of providing dynamic reactive power compensation ability and, improving the electric energy quality of Zhoushan Power Grid, reliving the grid connection problem of wind power fields in Zhoushan islands and improving the flexibility of the power grid dispatching and operation. The construction and implementation of this project can also provide a good reference in technology and engineering for the future power supply of offshore islands, grid integration of renewable energy sources, multi-terminal DC transmission system, even construction of DC grids and other applications.

In Guangdong Nan'ao wind power field, a three-terminal HVDC Flexible project [26] is under construction now. Because a large number of wind turbine generators are installed around Nan'ao Island, in order to achieve integrating the wind power, two wind farms are firstly planned to be connected into the two-terminal convertor station through a $110 \mathrm{kV}$ transformer substation. The power energy will be transmitted to Shantou Power Grid after being collected by the HVDC Flexible system. Nan'ao project has a DC voltage of $\pm 160 \mathrm{kV}$ and a rated transmitting power of $200 \mathrm{MW}$. Its system diagram is as shown in Fig. 14.

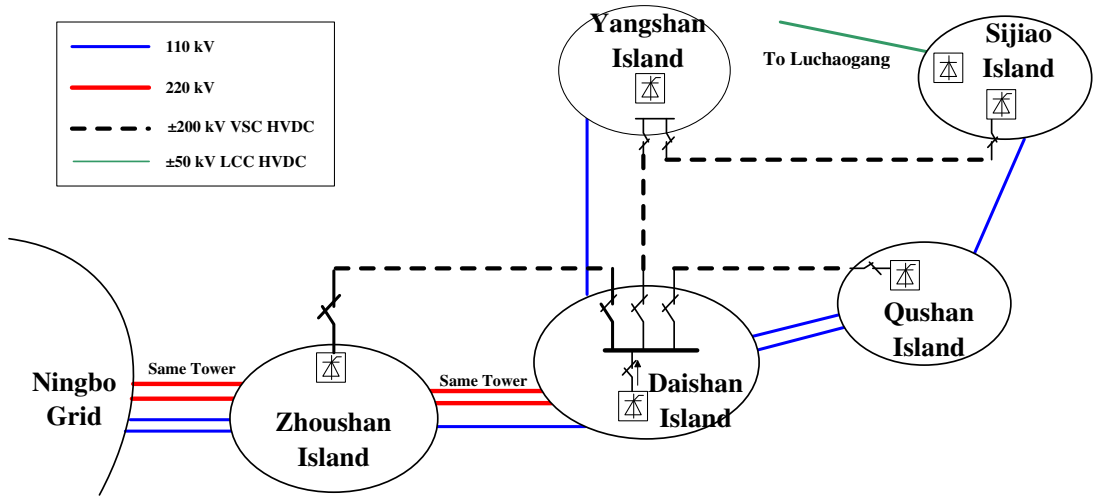

Fig. 13 Diagram of Zhoushan five-terminal HVDC Flexible project 


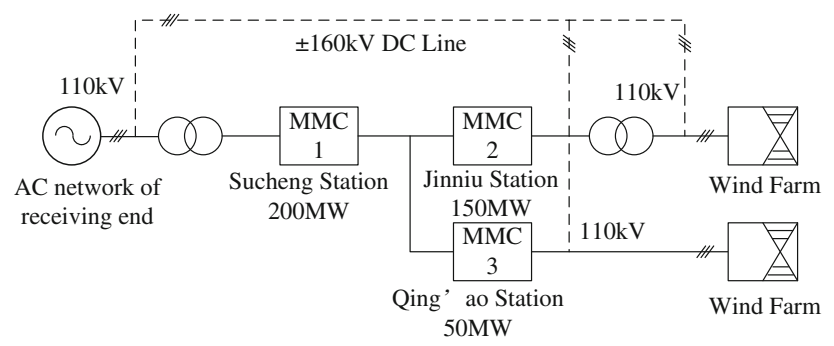

Fig. 14 Diagram of Nan'ao three-terminal HVDC Flexible project

\section{Future development trend of HVDC flexible}

The rapid progress of the HVDC Flexible technology promoted their applications in wind power integration, grid interconnection and other situations, while the development of market drives the improvement of the technique levels in return. From the current application demands, we can find that the main development directions of future HVDC Flexible technologies include: High-capacity HVDC Flexible technique, DC grid technique and overhead line HVDC Flexible technique.

\subsection{High-capacity HVDC flexible technologies}

Integration of large wind farms and urban loads, power grid interconnection and other application situations put forward higher requirements on the transmission capacity of HVDC Flexible. Currently, the world's largest HVDC Flexible project is $1,000 \mathrm{MW} / \pm 320 \mathrm{kV}$. In 3 to 5 years, the projects of $1,200 \mathrm{MW} / \pm 400 \mathrm{kV}$ and higher will be implemented soon.

Technically, the improvement of voltage level and capacity of the current HVDC Flexible system is mainly restricted by the voltage level of the XLPE cables and the development of the existing IGBT devices. In previous projects, the use of single converter also limited the increase of the system capacity. Therefore, the capacity improvement of the future HVDC Flexible will mainly concentrate on the XLPE cables with higher rated voltages, new type high-capacity power electronic devices, new system topology applications and other aspects.

\section{1) XLPE cable technology}

On the choice of cables, comparing to XPLE cables, MI cables can be considered to be used in the higher capacity HVDC Flexible projects. This kind of cables has higher voltage levels, but the fabrication cost is relatively higher, which makes them difficultly be promoted in great range. Therefore, it will still need a breakthrough in XLPE cables in the future.

On the aspect of XLPE cables, the main difficulties faced currently are the charge distribution and manufacturing technique of the cable insulating materials and the design and process of the cable connectors. The principal cable manufacturers in the world all have put a great development effort on this aspect. At present, the $\pm 500 \mathrm{kV}$ XLPE cables are at the test phase and are expected to be put into project application in the next 2 to 3 years. With the continuous promotion of the future projects, XLPE cables of higher voltage levels may also appear. It is expected that in 5 years, the voltage and capacity levels of XLPE DC cables will be promoted to $600 \mathrm{kV} / 2 \mathrm{GW}$, and in 10 years, the voltage and capacity levels of DC cables will reach more than $750 \mathrm{kV} / 3 \mathrm{GW}$.

\section{2) Power electronic device technology}

To improve the capacity of IGBT devices, it is required to solve the problems in the fabrication and encapsulation of IGBT chips due to the increase of voltage and current. It will be faced with quite high difficulty to substantially improve the production technique at the same time of ensuring the product reliability. At present, the main device manufactures in the world are carrying out research and development on the IGBT devices of high voltage and large current levels, which are expected to be put into commercial utilization in the next few years. Meanwhile, in the application process of the devices, a series of technological difficulties shall be solved, such as the driver design of new type IGBT, the overshoot suppression of current turn-off, the quick protection design and so on. These difficulties need to be solved by careful design and longterm tests for verification.

In respect of new type semiconductor devices, "large energy gap" semiconductor materials (such as silicon carbide $(\mathrm{SiC})$, etc) are a kind of materials with the best development prospect in the future. That is why the power semiconductor devices have currently become one of the research hotspots in the worldwide. Compared with the existing devices, IGBT devices made of this kind of materials will be promoted several to tens of times on the aspects of voltage withstand level, through-current capacity, operating temperature and so on. And meanwhile, the losses will only be a fraction of that of the traditional silicon devices. Converters and systems constituted upon this kind of devices will directly make the existing engineering capacity improve several to tens of times, which will bring revolutionary change to the development of HVDC Flexible. But due to lots of problems existed in the quality and technique control and other aspects of $\mathrm{SiC}$ and equivalent materials currently, the process is just remained at the sample and product phase of small capacity. In the short term, they are unable to be really put into project application of large capacity. It is expected that $\mathrm{SiC}$ and equivalent devices will be put into a certain scale of demonstration application in the electric power system in 20 years. 


\section{3) Combined type system topology technique}

Because cable and device development cycle is relevant long, if projects in the short term need to increase the capacity, two kinds of schemes can be used. One is in the form of converter combination; and the other is to use full bridge type converters constituted by sub-modules which makes the use of negative level output to increase AC voltage level, so as to upgrade the system capacity. But both kinds of schemes will increase the systematic costs.

The basic approaches of multiple converter combination include: series connection, parallel connection or seriesparallel connection and so on, which are basically the same as the multiple converter scheme used in conventional DC transmission. The system structure of multiple converter combination can not only reduce the requirements of the circuital insulating level and improve the system reliability under the fault circumstances, but also facilitate the construction of the staging projects (such as Caprivi Link project). In addition, in the present HVDC Flexible projects, VSCs are used in both terminals of each system. But other forms of converter station structures also have high feasibility in special situations, such as the use of hybrid DC with current sourced converter (CSC) and VSC at each of the two terminals respectively, or the use of CSC and VSC for the two converters in a convertor station, etc [2729]. Some schemes in these system structures have been used in several projects (such as Skagerrak4 project and GBX project and so on).

Based on the current technologies with the addition of the combined topology applications, the voltage level of the HVDC Flexible system can be directly improved to $\pm 640 \mathrm{kV}$ or above, in which single converter capacity can be promoted to 2,000 MW. However, if considering using the combination of series-parallel connection of converters, for example using eight $320 \mathrm{kV}, 1 \mathrm{kA}$ converter units in which every two units will be connected in parallel first then in series. In such combination the voltage level will reach $640 \mathrm{kV}$ and the total capacity will reach 2,560 MW. If the series-parallel connection units are recombined into a double pole system, the system parameter will achieve $640 \mathrm{kV} / 5,120 \mathrm{MW}$.

\subsection{Multi-terminal DC and DC grid technologies}

With the continuous development of renewable energy sources as well as the demands of existing grid upgrade and other aspects, the future development of HVDC Flexible will continue to focus on the networking and concentrated on transmission of wind power, local grid interconnection, electric power transmission to urban center load and other aspects. In many cases these applications need to realize the power supply of multiple power input and output points, thus the multi-terminal DC and even DC grid technologies are required to be used.

\section{1) Concepts of multi-terminal DC and DC grid}

Multi-terminal HVDC transmission (MTHVDC) is the primary stage of the DC grid development. It is a transmission system connected by more than three convertor stations through series, parallel or combination connection of parallel and series. It can realize multiple power input and output points. Because the HVDC Flexible has unique technical advantages in construction multi-terminal system, it will be rapidly developed in the MTHVDC system in the future.

The DC grid is equivalent to the extension of the MTHVDC. It is a stable AC/DC hybrid wide-area transmission network which has the intelligence of advanced energy management system. In the network, different clients, existing transmission networks, micro power grids and different power sources can get efficient management, optimization, monitoring and control, and real-time response to any problems. It can integrate multiple power sources and transmit and distribute the power energy with minimum losses and maximum efficiency in a larger range.

The most fundamental difference between DC grid and MTHVDC is that DC grid is a transmission system with "loops", there are multiple transmission circuits connected between each convertor stations and the whole system has redundancy and high reliability [30] (see Fig. 15). Therefore, the future development direction of MTHVDC shall be towards the development of network, i.e. DC based power transmission and distribution network.

2) Future development trend of DC grid

Specific to the development of DC grid, Europe has proposed a "Super Grid" to construct a new generation of transmission grid based on the HVDC Flexible technology

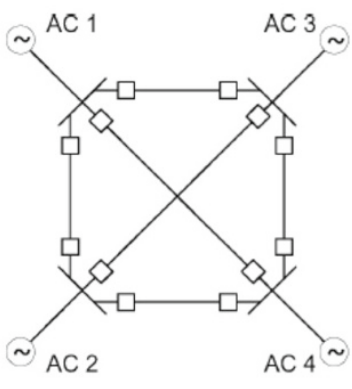

(a) MTHVDC system

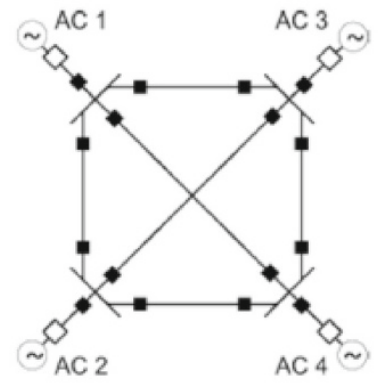

(b) DC grid

$$
\square \text { : Convertor stations; } \square \text { : DC breakers }
$$

Fig. 15 MTHVDC and HVDC grid 
and to, establish a wide-area intelligent transmission network. The aims of this proposal are to realize the power fluctuation suppression of renewable distribution generations in a wide-area range and large-scale efficient integration of renewable energy sources, guarantee the safe and stable operation of the power grids, improve the power supply quality, promote the harmonious development of renewable energy sources and power system and so on [3133]. China can also construct DC grids based on the largescale offshore wind farms in the future.

\section{3) DC grid technology and equipment development}

It shall be noted that the DC grid is still at the beginning development stage. There are lots of critical issues needing to be solved, such as standardization of the DC grid and equipment, development of core equipment, control technology, wide-area measurement and fault detection technologies, protection technology, the safety and reliability assessment techniques of the DC grids, etc.

From the current technique development point of view, the following problems need to be solved emphatically before the DC grids are really put into application.

First is to solve the DC circuit fault isolation problem. The main $\mathrm{R} \& \mathrm{D}$ direction is the new converter topologies. Because the MTHVDC and HVDC grid may need the converters to realize the DC fault self-clearance and other functions. The hot issue of the current research is how to improve and even develop brand new converter topologies on the basis of the existing topological structures, so as to meet the application demands of these occasions. At present, the topologies which can be used in the multiterminal system and have DC fault clearance function are not only the currently used full bridge sub-module topology, but also new type converter topological structures developed by many institutions and scholars, e.g. the one based on the full bridge or CDSM (clamping double submodules) [34]. The hybrid topology scheme proposed by Alstom can not only reduce the systematic costs efficiently, but also restrain the DC fault current so as to realize fault clearance, which is also one of the research hotpots now.

Second is to develop DC breakers to be applied in the DC system. Specific to the DC breakers, corresponding prototype design and development have been carried out in the worldwide. At present, $\mathrm{ABB}$ and Alstom have already finished the prototype tests. Companies in China are also carrying out relevant development and are expected to launch relevant products in the next 2 to 3 years [25].

Third is to solve the interconnection problems of DC grids at different voltage levels. The main solution is to research and develop appropriate DC transformers. Regarding to the DC transformers (DC/DC convertors), there are no relevant products which have been launched yet in the world. Some research organizations in China are carrying out basic research and conceptual design now. It is expected to still need certain time to launch the products.

\subsection{Long distance overhead line HVDC Flexible technology}

HVDC Flexible technology in the cases that overhead lines are used as the transmission circuits has extensive application prospect as well. The use of overhead line transmission can not only increase the voltage level and system capacity, but also efficiently reduce the circuit investment and save the construction costs. As China has vast territory, the resource allocations of the electricity generation and utilization in various regions are serious unbalance. Therefore, the long distance overhead line power transmission plays an irreplaceable role in the process of the electric power development in China.

The use of overhead line transmission system needs the fault clearance ability which is required to solve the transient faults in the circuits. In addition to developing DC breakers with corresponding voltage levels, the problem can be solved by developing new type converter topologies which can clear the DC faults. This is the same as the requirements of the $\mathrm{DC}$ grids.

Meanwhile, normally the conventional HVDC system is used at the sending-end terminal and HVDC Flexible at the receiving-end terminal in the overhead line transmission system, or the conventional HVDC converter stations are converted into HVDC Flexible stations. It is an important development direction of using the HVDC Flexible in the overhead line transmission systems to solve the commutation failures caused by the system faults at the same time of saving the construction costs.

\section{Conclusions and prospects}

The increasing promotion of the requirements against the global climate change and the increasingly severe security situation of energy supply urgently require the construction of more intelligent, clean, efficient and reliable transmission grid, which has become the common goal of various countries in the world to develop the electric power industry. The HVDC Flexible technology attracts more and more researchers' attention due to its advantages of active and reactive power independent adjustment, black start capacity, easily constructing DC grid etc. Meanwhile, the constantly improving technical level of controllable switch devices, DC cables and other equipment has efficiently enhanced the transmission capacity of HVDC 
Flexible and made HVDC Flexible become one of the main transmission modes used by the power grids. It is predicated that with the demands of integration of renewable energy sources and power grid transformation and upgrade in the future, the HVDC Flexible applications in China will gain increasingly wide development.

Due to the influence of regional and economic development, European countries generally face significant problems such as the power supply corridor tensions and energy structure adjustment. The construction of large scale DC grids is conductive to the optional configuration of energy sources and can solve the potential system safety hazards caused by wide-range wind power integration. The HVDC Flexible technology has a rapid development as the prior choice of wind power integration and DC grid construction. It is predicted that regional DC power grid with the foundation of HVDC Flexible, the backbone network of $500 \mathrm{kV}$ or higher and the main transmission capacities of $10 \mathrm{GW}$ and above will be built in Europe in the next 10 to 20 years.

In China and other countries with vast territories, the extra-high voltage AC/DC transmission technologies are still the efficient means to solve the long distance and high capacity electricity transmission problems. But for the grid integration and digestion and save problems of regionally new energy sources, the HVDC Flexible and DC grid technologies will be effective supplements. The next 10 years will be the rapid development and construction phase for the HVDC grid technology. As the capacity of the HVDC Flexible system is continuously increased, it is an irresistible trend that the HVDC Flexible system will gradually replace the conventional HVDC and HVAC transmission systems in some fields in the future.

Acknowledgement This work was supported by National Natural Science Foundation of China (No. 51261130471).

Open Access This article is distributed under the terms of the Creative Commons Attribution License which permits any use, distribution, and reproduction in any medium, provided the original author(s) and the source are credited.

\section{References}

[1] State Grid Corporation of China (2009) Research report on the clean energy development advanced by SGCC, Beijing, China, 2009 (in Chinese)

[2] Tang GF, He ZY, Cao JZ et al (2012) A review of 2012 CIGRE on application and perspective in HVDC and power electronics. Autom Electr Power Syst 36(24):1-6 (in Chinese)

[3] Flourentzou N, Agelidis VG, Demetriades GD (2009) VSCbased HVDC power transmission systems: an overview. IEEE Trans Power Electr 24(3):592-602
[4] Tang GF (2010) Voltage source converter based HVDC transmission technology. China Electric Power Press, Beijing (in Chinese)

[5] ABB HVDC Light. http://new.abb.com/systems/hvdc/hvdclight. Accessed 31 Dec 2012

[6] Marquardt R, Lesnicar A (2004) New concept for high voltage-modular multilevel converter. In: Proceedings of the 2004 IEEE power electronics specialists' conference (PESC'06), Aachen, Germany, 20-25 June 2004, p 5

[7] Ding GJ, Ding M, Tang GF (2009) Analysis and comparison of VSC-HVDC topologies and corresponding modulation schemes. Automat Electr Power Syst 33(10):64-68 (in Chinese)

[8] Working Group B4.37 CIGRE (2005) DC transmission using voltage sourced converters. Technical Brochure No. 280, International Council on Large Electric Systems, Paris

[9] Ding GJ, Tang GF, Ding M (2009) Topology mechanism and modulation scheme of a new multilevel voltage source converter modular. P CSEE 29(36):1-8 (in Chinese)

[10] Ding GJ, Ding M, Tang GF et al (2009) A new hybrid PWM technology used in the VSC-HVDC transmission system. Power Syst Technol 33(7):7-13 (in Chinese)

[11] Henry S, Denis AM, Panciatici P (2010) Feasibility study of offshore HVDC grids. In: Proceedings of the 2010 IEEE power and energy society general meeting, Minneapolis, 25-29 Jul 2010, p 5

[12] Wang SS, Zhou XX, Tang GF et al (2011) Modeling of modular multi-level voltage source converter. P CSEE 31(24):1-8 (in Chinese)

[13] Knaak HJ (2011) Modular multilevel converters and HVDC/ FACTS: a success story. In: Proceedings of the 14th European conference on power electronics and applications (EPE'11), 30 Aug-1 Sept 2011, Ludvika, pp 2498-2503

[14] Jacobson B, Karlsson P, Asplund G, et al. (2010) VSC-HVDC transmission with cascaded two-level converters. B4-110, CIGRE, Paris

[15] Wang SS, Zhou XX, Tang GF et al (2011) Selection and calculation for sub-module capacitance in modular multi-level converter HVDC power transmission system. Power Syst Technol 35(1):26-32 (in Chinese)

[16] Wang SS, Zhou XX, Tang GF et al (2011) Influence of AC system strength on operating characteristics of MMC-HVDC system. Power Syst Technol 35(2):17-24 (in Chinese)

[17] ZhaoY HuXH, Tang GF et al (2011) Control strategy of modular multilevel converters based HVDC transmission. P CSEE 31(25):35-42 (in Chinese)

[18] Dong YL, Bao HL, Tian J et al (2011) Control and protection system for VSC-HVDC. Automat Electr Power Syst 35(19):89-92 (in Chinese)

[19] Wei YF, Wei ZN, Sun GQ et al (2012) New HVDC power transmission technology: MMC-HVDC. Electr Power Autom Equip 32(7):1-9

[20] Ying QL (2012) The prospect of development of DC submarine cables in China. Electr Wire Cable 3:1-7 (in Chinese)

[21] Liu D, Tang GF, Zheng JC et al (2012) Small signal modeling and analysis of open-loop response time constant of MMC. P CSEE 32(24):1-7 (in Chinese)

[22] Liu D, Tang GF, He ZY (2013) Hybrid teal-time simulation technology for MMC-HVDC. Electr Power Autom Equip 33(2):68-73 (in Chinese)

[23] Qiao WD, Mao YK (2011) Overview of Shanghai HVDC flexible transmission demonstration project. East China Electr Power 39(7):1137-1140 (in Chinese)

[24] Ge WC, Gu HQ, He ZY (2012) Overview of Dalian HVDC flexible transmission demonstration project. Northeast China Electr Power 2:1-5 (in Chinese) 
[25] State Grid Corporation of China (2012) Zhejiang Zhoushan Islands multi-terminal HVDC flexible projects have been approved. http:// www.sgcc.com.cn/ztzl/newzndw/sdsf/04/271599.shtml. Accessed 26 Nov 2012 (in Chinese)

[26] Rao H (2013) Research and application of the high-power electronic technology in China Southern Power Grid. Southern Power Syst Technol 7(1):1-5 (in Chinese)

[27] Guo CY, Zhao CY, Montanari A (2012) Investigation of hybrid bipolar HVDC system performances. P CSEE 32(10):98-104 (in Chinese)

[28] Li GK, Li GY, Liang HF et al (2011) Research on a novel hybrid HVDC system. Power Syst Technol 35(2):82-86 (in Chinese)

[29] Yuan XF, Cheng SJ, Wen JY (2006) Simulation study for a hybrid multi-terminal HVDC system based on VSC and CSC. Automat Electr Power Syst 30(20):32-36 (in Chinese)

[30] Tang GF, Luo X, Wei XG (2013) Multi-terminal HVDC and DC-grid technology. P CSEE 33(10):8-17 (in Chinese)

[31] Vrana TK, Torres-Olguin RE, Liu B, et al. (2010) The North Sea Super Grid-A technical perspective. In: Proceedings of the 9th IET international conference on $\mathrm{AC}$ and $\mathrm{DC}$ power transmission (ACDC'10), Glasgow, 19-21 Oct 2010, p 5

[32] Jovcic D, Van Hertem D, Linden K, et al. (2011) Feasibility of DC transmission networks. In: Proceedings of the 2nd IEEE PES international conference and exhibition on innovative smart grid technologies (ISGT Europe'11), Manchester, UK, 5-7 Dec 2011, p 8

[33] Feltes JW, Gemmell BD, Retzmann D (2011) From smart grid to super grid: Solutions with HVDC and FACTS for grid access of renewable energy sources. In: Proceedings of the IEEE Power and Energy Society general meeting, Detroit, 24-29 Jul 2011, p 6

[34] Marquardt R (2011) Modular multilevel converter topologies with DC short circuit current limitation. In: Proceedings of the IEEE 8th international conference on power electronics and ECCE Asia (ICPE \& ECCE'11), Jeju 30 May-3 Jun 2011, pp 1425-1431

Guangfu TANG received the B.Eng. degree in electrical engineering from Xi' an Jiao Tong University, Shanxi, P.R. China, in 1990, and the M.Eng. degree and the Ph.D. degree in electrical engineering from Institute of Plasma Physics, The Chinese Academy of Sciences (ASIPP), in 1993 and 1996 respectively. During 1996-1998, he had a postdoctoral position with China Electric Power Research Institute (CEPRI), Beijing, P.R. China, and he was the vice director of China Energy Conservation Center. In 1998, he joined the CEPRI, where he led the Thyristor Controlled Series Compensator Group from 1998 to 1999, the Static Var Compensator from 2000 to 2001. Since 2002, he has been a professor level senior engineer of CEPRI. During the past 16 years, his research fields include the fault current limiter, the converter valve of high voltage or ultra high voltage in DC transmission system, and the voltage-source converter-high voltage dc (VSC-HVDC) transmission systems. Now, he is the vice chief engineer of CEPRI. He has published more than 110 papers, and won 70 patents in his research field. Dr. Tang is the recipient of the 2006 Second Award, and the 2008 First Award of the National Science and Technology Progress of P.R. China respectively. And he has obtained 6 Awards of the Provincial Scientific and Technological Progress Awards. He was the Convenor of 48 Working Group in the International Council on Large Electric Systems in 2007. Now, he sits on a committee of the IEEE/PES Narain Hingorani FACTS and Custom Power Award Committee.

Zhiyuan HE received the B.Eng. degree in electrical engineering from Sichuan University, P.R. China, in 2000, and the M.Eng. degree and the Ph.D. degree in electrical engineering from China Electric Power Research Institute (CEPRI), in 2003 and 2006 respectively. In 2006, he joined CEPRI, where he led the voltage-source converter based high voltage DC (VSC-HVDC) transmission systems Group, from 2008 to 2009, was the manager for CEPRI in the areas of HVDC Technology. Since January 2010, he has been the manager and chief engineer for CLP Power Engineering CO., LTD PURELL of CEPR In the past six years, he has accomplished theoretical study on high power electronics technology for reliable operation of large interconnected power grids, relocatable DC de-ice system and VSC-HVDC transmission, including the first VSC-HVDC project commissioning in 2011 in China. He has published more than 50 papers, and won 36 patents in his research field. And he has obtained 2 awards of the Provincial Scientific and Technological Progress Awards. Dr. He was as a member of CIGRE B4 Working Group 48, and researched on "Components Testing of VSC System for HVDC applications" from 2006 to 2009. During 2009-2010, he got as a member of IEC SC22F Working Group 19, and researched on "High-Voltage Direct Current (HVDC) Power Transmission Using Voltage Sourced Converters (VSC).

Hui PANG received the B.Eng. degree and the M.Eng. degree in electrical engineering from Hefei University of Technology, P.R. China, in 2002 and 2005 respectively, and the Ph.D. degree in electrical engineering from China Electric Power Research Institute (CEPRI), in 2010. In 2010, he joined CEPRI, where he be a research of the voltage-source converter based high voltage DC (VSC-HVDC) transmission systems R\&D department, from 2011 to 2012, was the project manager in the areas of VSC-HVDC electrical design. Since 2013, he has been the manager of system R\&D of HVDC technology research department in Smart Grid Research Institute of SGCC. In the past 6 years, he has accomplished theoretical study on high power electronics technology, VSC-HVDC transmission and DC grid technology, including the first VSC-HVDC project commissioning in 2011 in China. 